\title{
Autorregulação da aprendizagem em contexto escolar: uma abordagem baseada em Ateliês Biográficos de Projetos ${ }^{*}$
}

\section{Self-regulation of learning in a school context: an approach based on Project Biographical Workshops}

\author{
Fabiane Puntel Basso** \\ Maria Helena Menna Barreto Abrahão**
}

\begin{abstract}
RESUMO
Este artigo teve o objetivo de compreender, por meio das narrativas autobiográficas, como os sujeitos percebem-se e constituem-se como agentes da própria formação no cotidiano de experiências escolares, através do processo da aprendizagem autorregulada. A pesquisa foi realizada em duas escolas da Rede Estadual de Ensino Fundamental, localizadas no município de Porto Alegre-RS. Participaram desse estudo 30 alunos do $9^{\circ}$ ano do Ensino Fundamental. A abordagem metodológica foi baseada nos ateliês biográficos de projetos. Foram organizadas sete sessões em grupos de $5 \mathrm{a}$ 10 alunos, com duração de 45 minutos cada uma. Todas as etapas foram realizadas no ambiente escolar. A análise dos resultados foi realizada por meio de um ângulo diferenciado e inovador, inspirado na compreensão cênica. Os resultados evidenciaram três cenas que revelaram as relações dos múltiplos sujeitos envolvidos, a compreensão de si por meio da escuta do outro e as cenas esquecidas ou reprimidas. As etapas vivenciadas nos ateliês ajudaram os alunos participantes a compreenderem como eles se constroem enquanto alunos e como se auto-organizam para regular suas aprendizagens, para superar obstáculos e para se adaptarem ao mundo escolar. Concluiu-se
\end{abstract}

DOI: $10.1590 / 0104-4060.49420$

* Pesquisa financiada pelo Conselho Nacional de Desenvolvimento Científico e Tecnológico (CNPq).

** Universidade Federal de Pelotas, Faculdade de Educação. Pelotas, Rio Grande do Sul, Brasil. Rua Alberto Rosa, $154-2^{\circ}$ andar. Várzea do Porto. CEP: 96.101-770. E-mail: fabiane. basso@gmail.com; abrahaomhmb@gmail.com 
que a abordagem inspirada nos ateliês biográficos de projetos pode auxiliar na reflexão dos processos de autorregulação da aprendizagem, inserindo-se adequadamente numa dinâmica evolutiva do percurso educativo.

Palavras-chave: Pesquisa autobiográfica. Ateliês biográficos de projetos. Autorregulação da aprendizagem.

\begin{abstract}
This goal of this article is to understand, using autobiographical narratives, how the subjects perceive and constitute themselves as agents of their own development in the daily life of school experiences, through the process of self-regulated learning. This research was carried out in two public elementary schools, located in the city of Porto Alegre-RS. Thirty students from the 9th grade participated in these studies. The methodological approach was based on the project biographical workshops. The students were organized in groups of five to ten, in seven sessions, each lasting 45 minutes. All steps were taken in the school environment. The analysis of the results was carried out through a differentiated and innovative angle inspired by scenic comprehension. The results demonstrate three scenes that revealed the relationships of the multiple subjects involved, the understanding of themselves through the listening of the other and scenes that were forgotten or repressed. The steps in the workshops helped the participating students to understand how they are built as students and how to organize themselves to regulate their learning, to overcome obstacles and to adapt to the school world. We concluded that the approach inspired by the project biographical workshops could help in reflecting about the processes of learning selfregulation, inserting itself appropriately in an evolutionary dynamic of the educational path.
\end{abstract}

Keywords: Autobiographical research. Project biographical workshops. Learning self-regulation.

\title{
Introdução
}

A autorregulação da aprendizagem é um conceito importante no processo de construção de conhecimento de escolares, uma vez que envolve diferentes esferas do funcionamento humano, considerando o indivíduo como um sujeito que atua e sofre influências de diferentes dimensões, como ambientais, pessoais e comportamentais (ZIMMERMAN, 2013; BANDURA, 2008). Esse processo conduz a uma aprendizagem mais autônoma e ativa, em que o aprendiz utiliza 
suas capacidades pessoais e estratégias adaptadas a cada situação para maximizar a sua aprendizagem (ZIMMERMAN, 2000).

Muitos pesquisadores (COSNEFROY, 2013; FRISON; VEIGA SIMÃO, 2011) salientam que a aprendizagem escolar pode ser mais eficiente se o aluno consegue ser capaz de definir objetivos e gerenciar seu tempo de estudo de maneira mais autônoma e pró-ativa. De acordo com Cosnefroy (2013), alunos que possuem essa capacidade de se autorregular na aprendizagem são mais preparados para aprender ao longo de toda a vida. De fato, a capacidade de se autorregular é um processo bastante complexo e dinâmico (BASSO; ABRAHÃO, 2017, no prelo), que resulta da interação de variáveis como conhecimento, competência e motivação, e possibilita que o estudante consiga gerenciar os sistemas de planejamento, organização, controle e avaliação dos processos adotados, dos resultados atingidos e das variáveis contextuais (SILVA; VEIGA SIMÃO, 2016). Esses aspectos estão relacionados ao processo de autorreflexão, pois, ao aprofundar o conhecimento de si, o aluno também possibilita uma melhor compreensão da sua própria maneira de autorregular a aprendizagem.

A pesquisa autobiográfica e, mais especificamente, os Ateliês Biográficos de Projetos - ABPs (DELORY-MOMBERGER, 2006, 2007) proporcionam essa autorreflexão do sujeito e, dessa forma, podem intervir no desenvolvimento da autorregulação da aprendizagem. As narrativas orais e escritas são meios de reflexão e instrumentos de introspecção (GOHARD-RADEKOVIC; RACHÉDI, 2009) suscetíveis de fazer compreender como os estudantes percebem-se e constituem-se como agentes da própria formação no cotidiano de experiências escolares, através do processo da aprendizagem autorregulada. O estudo da aprendizagem autorregulada por meio de uma abordagem autobiográfica baseada em ateliês (ABPs) ainda é inexistente na literatura. Essa interação entre a autorregulação da aprendizagem e a pesquisa autobiográfica é uma alternativa para compreender de maneira mais profunda o processo de autoformação (ABRAHÃO; FRISON, 2010; FRISON; VEIGA SIMÃO, 2011).

Segundo Basso, Abrahão e Frison (2015), o aluno vivencia de maneira singular sua integração no mundo da escola em função da sua história de vida, das relações com seus pares, membros da família, professores etc. A forma como o aluno se autobiografa, seja narrando fatos da vida relacionados ou refletindo sobre o processo de autoformação, mostra a sua postura face às aprendizagens, como ele se constrói no papel de aluno e como ele utiliza a aprendizagem autorregulada para desenvolver suas capacidades relacionadas à aprendizagem. Nessa perspectiva, este artigo buscou compreender o processo de autorregulação da aprendizagem em estudantes do $9^{\circ}$ ano do Ensino Fundamental, observando, por meio das narrativas orais e escritas do ABP, como os fatores internos (emoções, motivações, imagem de si, engajamento etc.) e externos (práticas 
pedagógicas utilizadas pelos educadores, contextos educacionais etc.) podem influenciar no processo de autorregulação da aprendizagem e na apropriação do conhecimento escolar.

\section{Método}

O cenário deste estudo foi constituído por duas escolas da Rede Estadual de Ensino Fundamental, localizadas no município de Porto Alegre-RS. A investigação foi realizada durante dois anos, no primeiro ano na escola A e no segundo ano na escola B. Ao longo da pesquisa, participaram 30 alunos do $9^{\circ}$ ano do Ensino Fundamental II (10 da escola A e 20 da escola B). No total foram 12 indivíduos do sexo feminino e 18 do sexo masculino. As idades variaram de 14 anos e 3 meses a 18 anos e 6 meses. Os alunos do $9^{\circ}$ ano foram escolhidos como sujeitos dessa pesquisa por fazerem parte de uma etapa delicada da aprendizagem escolar. Nesse período final do Ensino Fundamental, os alunos aprofundam os conhecimentos adquiridos no ciclo anterior e iniciam os estudos das matérias que serão a base para a continuidade no Ensino Médio. Foi escolhida esta etapa da escolarização por ser uma fase repleta de mudanças, em que os jovens começam a buscar autonomia de forma mais intensificada, razão pela qual a aquisição de competências autorregulatórias da aprendizagem pode ser de significativa valia para os alunos nessa faixa etária tornarem-se mais independentes em seu esforço de aprender.

\section{Descrição dos instrumentos e procedimentos}

Para atingir os objetivos da pesquisa, foi utilizada uma abordagem empírica e qualitativa que se inscreve no campo da pesquisa pedagógica (PERRENOUD, 1999), com ênfase na aprendizagem autorregulada (VEIGA SIMÃO; FERREIRA; DUARTE, 2012; ZIMMERMAN, 2000) e ao mesmo tempo no campo da pesquisa autobiográfica (ABRAHÃO, 2004; DELORY-MOMBERGER, 2003, 2009; DEMAZIÈRE; DUBAR, 2004; JOSSO, 2006; LEGRAND, 1993; PASSEGGI; ABRAHÃO; DELORY-MOMBERGER, 2012; BOUDAOIUN, 2010). A abordagem metodológica é inspirada no ateliê biográfico de projetos de Delory-Momberger $(2006,2007)$ e descrita em Basso, 
Abrahão e Frison (2015) e Basso (2016). As etapas dos ateliês biográficos de projetos foram adaptadas ao objetivo da pesquisa, acarretando modificações das etapas a fim de melhor aprofundar os aspectos relacionados à aprendizagem autorregulada. No primeiro ateliê (escola A), foram organizadas sete sessões em grupos de cinco alunos, com duração em torno de 45 minutos cada uma. No segundo ateliê (escola B), foram organizadas sete sessões em grupos de dez alunos, também com duração de 45 minutos cada uma. Todas as etapas foram realizadas no ambiente escolar, em sala de aula ou em salas disponíveis nas bibliotecas das escolas. Os encontros foram previamente arranjados com os professores envolvidos ou com as diretoras das escolas para se adequarem ao calendário escolar e não atrapalharem o desenvolvimento das disciplinas. Assim, as etapas dos ateliês envolveram sete encontros que objetivaram a reflexão sobre as estratégias autorreguladoras na atividade de estudo, a socialização dessas reflexões e a mobilização de novas estratégias autorregulatórias no projeto educacional de cada um. As sete etapas são apresentadas na Tabela 1.

\section{TABELA 1 - ATIVIDADES REALIZADAS EM CADA UMA DAS SETE ETAPAS DO ABP}

\begin{tabular}{|c|c|}
\hline $\begin{array}{l}\text { Etapas do } \\
\text { ABP }\end{array}$ & Atividades \\
\hline Primeira etapa & $\begin{array}{l}\text { - Encontro com o grupo de professores envolvidos na formação dos alunos do } 9^{\circ} \\
\text { ano para apresentar o projeto de pesquisa e discussão das atividades. }\end{array}$ \\
\hline Segunda etapa & $\begin{array}{l}\text { - Contato inicial com os alunos participantes da pesquisa e estabelecimento de } \\
\text { um contrato de participação com informações sobre os procedimentos, objetivos } \\
\text { e dispositivos que iriam ser colocados em práticas. } \\
\text { - Recuperação dos termos de consentimento esclarecido e assinatura dos termos } \\
\text { de assentimento para menores. }\end{array}$ \\
\hline Terceira etapa & $\begin{array}{l}\text { - Produção escrita de uma narrativa autobiográfica sobre o percurso escolar do } \\
\text { aluno, suas dificuldades ao longo da escolarização, as experiências no contexto } \\
\text { escolar e reflexões sobre as estratégias pessoais utilizadas no estudo. }\end{array}$ \\
\hline Quarta etapa & $\begin{array}{l}\text { - Socialização das autobiografias narrativas e discussão sobre os aspectos que } \\
\text { envolvem as experiências escolares e as estratégias autorregulatórias para a } \\
\text { aprendizagem. } \\
\text { - Reflexões norteadas por questões previamente formuladas. } \\
\text { - Reescrita por um escriba escolhido por cada aluno para realizar um } \\
\text { novo texto na primeira pessoa, a partir da narrativa e das intervenções do } \\
\text { participante. }\end{array}$ \\
\hline $\begin{array}{l}\text { Quinta e sexta } \\
\text { etapas }\end{array}$ & $\begin{array}{l}\text { - Apresentação de um projeto pessoal do aluno para a melhoria do seu processo } \\
\text { de estudo e de autorregulação. } \\
\text { - Relato de como as reflexões e discussões realizadas no grupo mobilizaram } \\
\text { novas estratégias autorregulatórias de como aprender a aprender. }\end{array}$ \\
\hline Sétima etapa & $\begin{array}{l}\text { - Finalização do projeto. } \\
\text { - Análise conjunta da incidência do ABP nas experiências escolares e no } \\
\text { processo de estudo de cada um. }\end{array}$ \\
\hline
\end{tabular}


O ateliê biográfico de projetos é uma forma de ter acesso aos discursos orais e escritos dos alunos, às suas formas de se autobiografar e ao sentido que eles dão à escola e aos conteúdos escolares. Buscou-se compreender como o aluno aprende a protagonizar suas ações, através da autorregulação do pensar, do aprender a aprender e da construção da sua identidade pessoal e escolar (FRISON; VEIGA SIMÃO, 2011).

$\mathrm{Na}$ investigação dos aspectos relacionados à autorregulação da aprendizagem, os ateliês buscaram evidenciar os percursos escolares dos alunos, as estratégias que os alunos utilizam para autorregular a aprendizagem geral, assim como a maneira que eles planejam suas vidas no futuro. Enfim, o objetivo dessa abordagem metodológica foi de observar como se desenvolve o processo de autorregulação ao longo da escolarização do $9^{\circ}$ ano e como essas estratégias autorregulatórias podem ser usadas na escola e ao longo da vida.

\section{O processo de análise}

A análise dos ABPs foi inspirada na compreensão cênica (SANTAMARINA; MARINAS, 1994; MARINAS, 2007, 2014). Esse tipo de abordagem é uma perspectiva alternativa para a interpretação e compreensão de dados qualitativos, principalmente quando são analisadas as narrativas orais e escritas da autobiografia, em que o sentido profundo dos relatos são construídos sistematicamente (ABRAHÃO, 2014).

A análise cênica foi recentemente desenvolvida por Abrahão (2014) e é atualmente utilizada em trabalhos da área da pesquisa autobiográfica (FRISON; BASSO, 2016). Esta abordagem de análise é denominada por Santamarina e Marinas (1994) como processo de "comprensión escénica" e é coerente com a corrente teórica que sustenta os processos de pesquisa autobiográfica, em razão de que, no processo de interpretação das informações, as dimensões da narratividade são entendidas como espaço de enunciação. A significação escénica privilegia, ao invés da estrutura amostral de uma história segundo o sentido originário dos textos ou dos elementos de profundidade de seus sentidos ocultos, o entendimento de que o sentido das falas é construído ao longo do processo de narração. Essa abordagem de análise utiliza principalmente a narrativa oral como fonte de objeto e atenção, mas pode ser utilizada também nas narrativas escritas, como é o caso do estudo realizado por Frison e Basso (2016). No presente estudo, utiliza-se as narrativas adquiridas por meio das etapas dos ateliês biográficos de projetos. 
Santamarina e Marinas (1994) e Marinas (2007) denominam três planos da compreensão cênica: o contexto passado, que comporta a totalidade de referenciais biográficos e sociais dos participantes da pesquisa; o contexto do presente dos indivíduos, que supõe as redes de relações sociais do presente dos sujeitos; e o contexto dos projetos futuros. Segundo Abrahão (2014), o contexto durante a entrevista ou durante o ateliê biográfico de projetos supõe as formas de acordo e cooperação para a efetivação da própria narrativa, seria uma relação de escuta e transmissão em reciprocidade como condição para a reflexão.

A compreensão cênica propicia a interpretação do processo no qual os participantes (estudantes) se "re-atualizam, re-elaboram o sentido, as posições ideológicas coletivas dos processos vitais" das histórias (SANTAMARINA; MARINAS, 1994, p. 272). Essa forma interpretativa compreensiva possibilita a aproximação das cenas constituintes dos contextos narrados, revelando cenas que envolvem o processo de autorregulação da aprendizagem, objetivo principal do presente estudo. De acordo com Frison e Basso (2016), com a utilização dessa abordagem, os elementos pertinentes vão se desenhando na medida da relação dos relatos com seus contextos. De acordo com Abrahão (2014), Marinas (2007), Santamarina e Marinas (1994), essa abordagem busca realizar uma articulação entre os elementos pessoais, sociais e institucionais mais amplos envolvidos na metodologia de pesquisa autobiográfica. Partindo dessa perspectiva, as etapas de socialização do ateliê biográfico de projetos aparecem como uma possibilidade de resgatar o sentido da autorregulação da aprendizagem do aluno, buscando evidências de questões relacionadas à formação, às experiências, às crenças e aos valores, manifestados nas falas de jovens estudantes.

Marinas (2007) ressalta ainda que a compreensão cênica é uma possibilidade de analisar os autorrelatos, os autodepoimentos, as autonarrativas, permitindo explorar o percurso escolar, experiências de aprendizagem, seu passado, traçar metas e planejar o presente a partir da reflexão e da discussão sobre a vida pessoal e o futuro profissional. Isto é possível por meio do compartilhamento de experiências do ateliê biográfico, reformulando questões vitais, fazendo novos encaminhamentos, ou seja, projetando o futuro. Todos esses processos estão inseridos dentro de um contexto, no tempo/espaço da escola, no qual passado, presente e futuro se imbricam (RICOEUR, 1995, 2007) para melhor compreender o processo de autorregulação e autoformação da aprendizagem.

Segundo Frison e Basso (2016), a cena três, descrita por Marinas (2007, 2014), explicita os momentos que fazem parte de uma entrevista ou de um repertório de cenas que pode envolver múltiplos sujeitos. Marinas $(2007,2014)$ explica a cena 1 (C1) como o momento da empatia, do relato não linear e cumulativo. A cena 2 (C2) é salientada como o momento da descrição dos fatos, dos movimentos de ir e vir das cenas relatadas. Esses movimentos entre as cenas 1 
e 2 permitem a compreensão da cena 3 (C3). A C3, segundo Marinas (2007), são as cenas reprimidas ou esquecidas, que estão implicitamente imbricadas nesse movimento de ida e vinda entre as cenas 1 e 2 .

\section{Resultados: as cenas que envolveram a compreensão de si por meio da escuta do outro}

A abordagem inspirada na compreensão cênica permitiu perceber aspectos importantes vivenciados nas cenas 1, 2 e 3 (Figura 1). Esse conjunto de cenas possibilitou uma melhor compreensão das estratégias autorregulatórias utilizadas pelos estudantes do $9^{\circ}$ ano do Ensino Fundamental das duas escolas, e como elas estão inseridas nos futuros projetos profissionais e pessoais.
FIGURA 1 - COMPREENSÃO CÊNICA DOS PROCESSOS AUTORREGULATÓ- RIOS OBSERVADOS DURANTE OS ATELIÊS BIOGRÁFICOS DE PROJETOS.

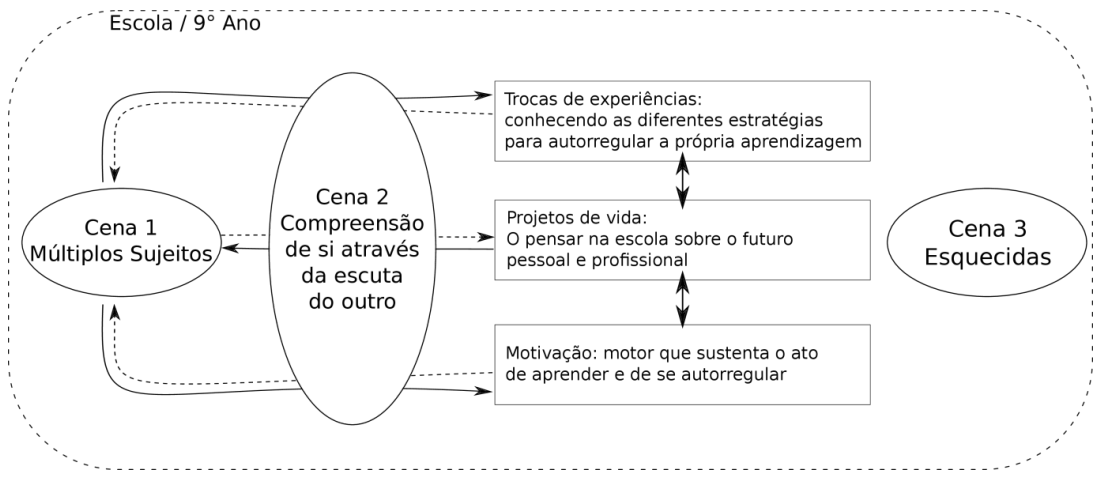

FONTE: Baseado em Marinas (2007) e Abrahão (2014).

Cena 1: múltiplos sujeitos e formas de expressão

A cena 1 corresponde às múltiplas conjunturas que foram observadas nas narrativas autobiográficas escritas e orais realizadas durante os ABPs. Todos os sujeitos, jovens alunos do $9^{\circ}$ ano das escolas A e B, participaram desse processo que permitiu identificar como os alunos fazem uso das estratégias autorreguladas 
na sua vida escolar e pessoal. As histórias de vida são retratadas nas narrativas dos alunos para explicar as escolhas pessoais nos seus processos de formação.

Assim, tanto as narrativas escritas como as narrativas orais fazem parte da cena 1, pois é o que reúne, no processo de escuta, os narradores e o pesquisador. Foram elaboradas questões que auxiliaram na iniciativa do debate e que facilitaram a participação dos estudantes. As questões temáticas que abordavam a atividade de estudo e também a atividade de produção escrita textual serviram como base para as reflexões. As questões norteadoras sobre as atividades de estudo e as estratégias utilizadas na vida cotidiana foram as seguintes: O que é estudar para você? Quais os motivos que levam você a decidir começar a estudar? Quando está fora da sala de aula e vai estudar, o que é que acontece? Quais são as estratégias utilizadas? Qual a tarefa que mais caracteriza o seu estudo? Qual é o momento de seu estudo em que sente mais facilidade ou dificuldade? Por quê? Como resolve?

A Figura 2 mostra um extrato retirado do texto autobiográfico da aluna A.R.G. e exemplifica o cenário das narrativas escritas. Nesse extrato ela enfatiza que não costuma estudar muito, mas quando estuda tenta ler e entender o conteúdo, e quando tem dificuldade pergunta para alguém ou procura na internet.

FIGURA 2 - EXTRATO DO TEXTO AUTOBIOGRÁFICO DA ALUNA A.R.G. (ESCOLA A), REALIZADA NA TERCEIRA ETAPA

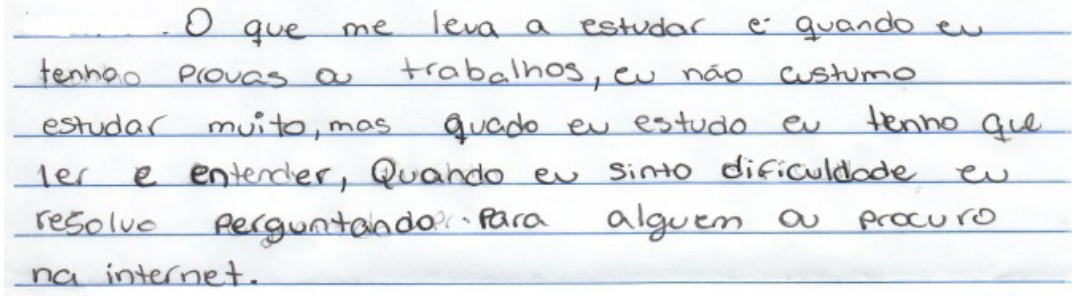

FONTE: Dados da pesquisa.

A Figura 3 exemplifica o texto autobiográfico da estudante J.M. Na narrativa escrita, entre outros pontos, ela relata como é a sua vida de estudante, exprime sua facilidade com os estudos e conta como conseguiu melhores desempenhos por meio da aquisição de novos hábitos. 
FIGURA 3 -EXTRATO DO TEXTO AUTOBIOGRÁFICO DAALUNA J.M. (ESCOLA B), REALIZADA NA TERCEIRA ETAPA

Para mim o estudo í algo relativamente facíl, tha mavoria dar vezer en estudo com a propóito de atinger notas mavores na escola, mas depous te um tempo torno-se hábito certa vez li que para alge se tornar um hábrto é necerrária repetir a acáo durante tiastor en seass seguidas. e foi isso que en biz duromte trinta ficar es estudei pelo monos so minutos, hoje en consigo ver melhor un pacosos sentada direto estudando, para apt

FONTE: Dados da pesquisa.

Esses exemplos evidenciam que as estratégias utilizadas pelos alunos em escolarização não se limitam às formas de organização institucionalizadas. Elas mostram toda a complexidade de experiências vivenciadas diariamente e, desta forma, interagem com o contexto de uma história escolar concreta. A Figura 4 ilustra o discurso do estudante que salienta a relevância do estudo para o futuro profissional e também expõe suas dificuldades e suas prováveis origens. Nesse exemplo o estudante relata as experiências ligadas ao "bullyng" que sofreu na escola durante os anos escolares anteriores e faz relação com as suas dificuldades acadêmicas e suas repetências.

FIGURA 4 - EXTRATO DO TEXTO AUTOBIOGRÁFICO DO ALUNO A.L.P. (ESCOLA A), REALIZADA NA TERCEIRA ETAPA

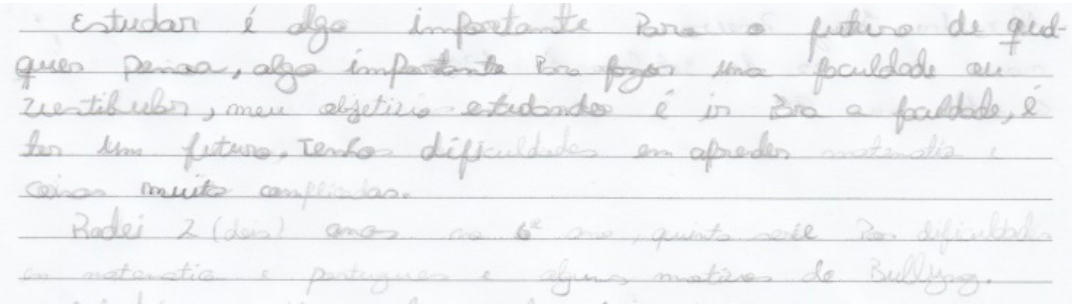

FONTE: Dados da pesquisa.

Esses extratos ilustram a cena 1: os múltiplos sujeitos e as múltiplas formas de expressão que mostram os contatos e os momentos da compreensão cênica, pelos quais são analisados os caminhos pessoais frente ao ato de aprender a 
aprender, de se autorregular para aprendizagens escolares e para a vida. Nessas cenas, a maioria dos contextos são marcados pelos depoimentos ligados às experiências pessoais, pelas estratégias de autorregulação que funcionam para um estudante, e que podem ser experimentados por outros colegas com o objetivo de identificar se também são adequadas para eles. Assim, nessas cenas estão inseridas um trabalho metacognitivo em que as estratégias se tornarão mais frutíferas e úteis no alcance dos objetivos de aprendizagem de cada um (BORUCHOVITCH, 2007).

\section{Cenas 2: compreensão de si por meio da escuta do outro}

$\mathrm{Na}$ abordagem autobiográfica, o contexto da escola e do ateliê é o espaço/ tempo especial de construção da fonte da pesquisa-formação, por meio da palavra dada e da escuta (MARINAS, 2007; ABRAHÃO, 2014). De acordo com Bragança (2014), a relação dialética entre a palavra dada e a escuta implica em que a palavra não é mais propriedade de quem fala, ao se dar coloca-se em um círculo virtuoso capaz de gerar novas interpretações, uma história que assim se abre. Assim, a partir da cena 1 foi possível compreender a cena 2. Os fatos autobiográficos da história de vida e acadêmica dos alunos podem ajudar a compreender o processo de autorregulação da aprendizagem e como essas trocas de experiências podem ser úteis no contexto de escolarização. Além da compreensão de si, a escuta do outro propicia o planejamento e ajuste em função de características pessoais, comportamentais e contextuais, uma vez que desenvolve o processo de autorreflexão. Três temáticas marcantes foram constatadas durante a análise das cenas que emergiram dos ateliês, elas são apresentadas a seguir.

\section{Trocas de experiência: conhecendo as diferentes estratégias para autorregular a própria aprendizagem}

Algumas etapas dos ateliês enfatizaram a socialização entre os participantes. Os discursos, as narrativas particulares, as histórias de experiências, de saberes práticos que, os meios da comunicação, podem auxiliar o desenvolvimento do próprio sujeito que se expressa como também o colega que, pela escuta dessa experiência, poderá ressignificar suas próprias vivências. Nessas trocas de experiências entre os estudantes, observou-se a relevância de falar sobre as diferentes estratégias de aprendizagem e suas dificuldades. As diversas estratégias discutidas durante os ateliês enfatizaram que cada aluno pode fazer uso de 
procedimentos ou atividades que mais se adaptam ao seu estilo de aprendizagem e que facilitam a apropriação do conteúdo e a assimilação dos conhecimentos obtidos no ambiente escolar. De acordo com Santamarinas (1994), as histórias de vida são formadas pelos relatos produzidos com intenção. Elaborar e transmitir uma melhor forma de aprender, seja pessoal ou coletiva, é uma maneira peculiar de intercâmbio que constitui todo o processo de investigação-formação.

A partir das Cenas 1, das narrativas orais e escritas, o conjunto de estratégias seguiu as caracterizações salientadas por Zimmerman e Risemberg (1997). Destacaram-se diversas estratégias que podem ser englobadas em quatro planos: comportamentais, cognitivas, metacognitivas e motivacionais, explicitadas em Basso, Abrahão e Frison (2015).

As estratégias comportamentais de autorregulação mais evocadas pelos estudantes foram: a) estratégias de seleção de modelos (obtendo informações através da internet, vídeos blogs, site como Wikipédia, entre outros; b) procura de apoio social (recorrendo à ajuda do professor, dos colegas).

As estratégias cognitivas e metacognitivas foram citadas por todos os estudantes. Elas foram explicadas, por exemplo, nas narrativas orais de B.C. e de E.B., respectivamente: "Tento prestar atenção e acompanhar a explicação do professor"; "Procuro observar as minhas dificuldades e focar meu estudo para prova da disciplina que não vou bem". Entre todas as estratégias cognitivas e metacognitivas, as mais frequentemente citadas foram as estratégias que envolviam a criação de um hábito de estudo, como refere J.M.: " $O$ que funcionou bem para mim foi criar uma rotina de estudo todos os dias, comecei com 10 minutos por dia e hoje consigo ficar duas horas focada no conteúdo".

Entretanto, é marcante nas narrativas dos estudantes que para eles o processo de aprendizagem que valoriza estritamente a concepção cognitiva não é suficiente para alcançar resultados satisfatórios na vida acadêmica e até mesmo na futura vida profissional. A motivação e o interesse para aprender são fatores tão importantes quanto as dimensões cognitivas. As estratégias motivacionais mais observadas foram aquelas relacionadas ao "passar de ano", ou seja, aquelas utilizadas quando o aluno começa a mudar sua atitude frente a sua aprendizagem em virtude do risco eminente de precisar "repetir de ano", o que acontece sobretudo no último trimestre do ano letivo. A escrita do estudante E.A.F. (Figura 5) exemplifica essa relação entre o uso de estratégia e a motivação extrínseca para passar de ano. 
FIGURA 5 - EXTRATO DO PROJETO DA ALUNA E.C.G. (ESCOLA A)

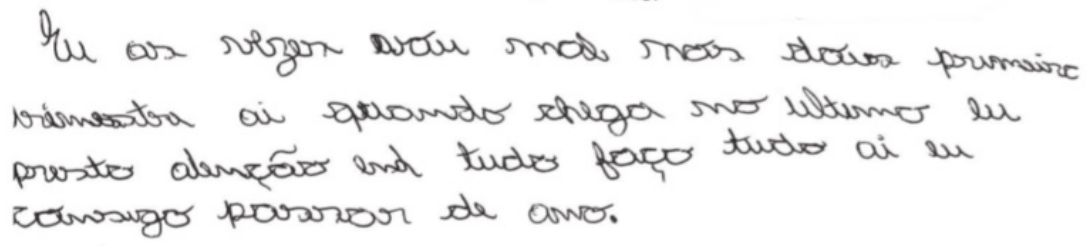

FONTE: Dados da pesquisa.

\section{Projetos de vida: o pensar na escola sobre o futuro pessoal e profissional}

A partir do ateliê e das atividades de compartilhamento das narrativas escritas e orais, os estudantes conseguiram elaborar o projeto final de construção dos planos pessoais e profissionais futuros, que envolveram os processos de autorregulação. A Figura 6 apresenta um exemplo de parte do projeto elaborado pela estudante E.C.G. que mostra os objetivos a curto prazo para seus estudos. Nesse extrato a estudante escreve que almeja conseguir uma bolsa de estudos em uma escola particular para ter mais chances de cursar uma faculdade e conseguir uma boa profissão.

FIGURA 6 - EXTRATO DO PROJETO DA ALUNA E.C.G.

Quero muito conseguir uma belsa de estudos para Particular com mais aprendizados.

FONTE: Dados da pesquisa.

A Figura 7 ilustra parte do projeto do aluno D.B.A. e faz essa relação entre os processos autorregulatórios da aprendizagem e a construção dos objetivos pessoais e profissionais no projeto final. Nessa parte do texto, o estudante expõe quais as estratégias que já começou a usar para conseguir atingir os seus objetivos. A partir de tudo que foi discutido com a turma, o que mais se 
encaixou no seu estilo de aprendizagem foi a visualização de vídeos aulas e a resolução de exercícios. Essas estratégias foram eleitas pelo aluno para suprir as dificuldades quando ele não entendia uma matéria ensinada pela professora.

FIGURA 7 - EXTRATO PROJETO DO ALUNO D.B.A.

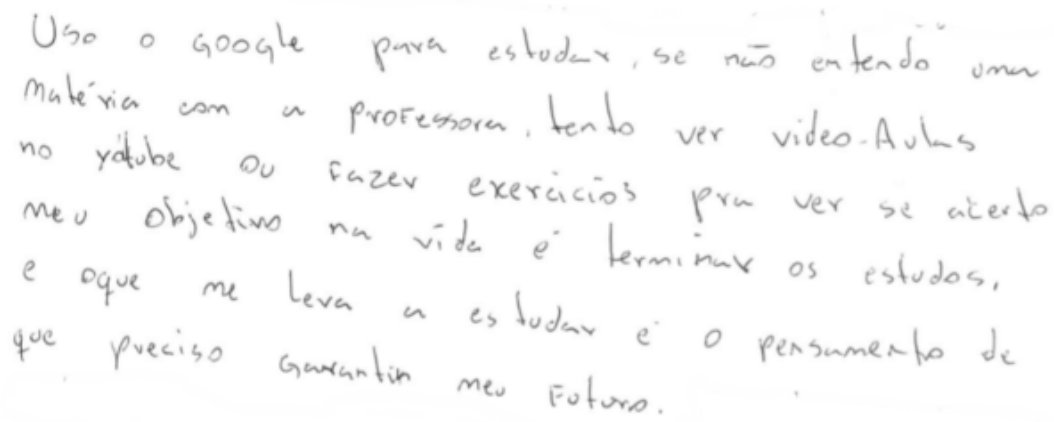

FONTE: Dados da pesquisa.

As narrativas dos estudantes mostraram que o trabalho biográfico de projetos estimula a formação a partir de um movimento dinâmico da prospectiva de mudança ao dar forma a um projeto de vida ou profissional. Esses projetos, ao inscreverem-se no espaço escolar e ao mesmo tempo social, encontra sua realidade e se realiza na capacidade de mudança do sujeito. (DELORY-MOMBERGER, 2006).

\section{Motivação: motor que sustenta o ato de aprender e de se autorregular}

Apesar dos estudantes que participaram do estudo terem objetivos de vida coletivos, como por exemplo, ter uma profissão, terminar o Ensino Médio, conseguir um bom emprego, observou-se, mesmo com algumas exceções, que o nível de motivação para atingir tais objetivos estava muito baixo nessas turmas. Esse fato pode ser notado na fala de E.B. quando ela relata: "eu não tenho vontade e nem interesse em estudar, eu tenho muita preguiça, eu já falei para minha mãe que eu devo ter algum problema porque a única coisa que eu gosto de fazer é dormir".

Em todas as fases do ABP, foi constatada a influência do componente motivacional sobre o processo aprendizagem. A motivação é um construto im- 
portante que dá força e energia para mobilizar o ato de aprender. Se o estudante não reconhece a importância do aprender, se ele não tem interesse ou não se sente competente para isso, ele não estará preparado para empregar de forma completa todas as suas competências cognitivas, metacognitivas e comportamentais fundamentais para desenvolver suas habilidades escolares.

Todo estudante, em níveis variados, é capaz de autorregular sua aprendizagem, isto é, monitorar, regular e controlar sua cognição, motivação e comportamento tendo em vista seus objetivos. (SAMPAIO; POLYDORO; ROSÁRIO, 2012). Entretanto, inúmeros estudos já mostraram que a autorregulação pode ser menos eficiente, ou ser realizada de modo inadequado, quando a motivação está alterada, o que pode levar a prejuízos no desenvolvimento da aprendizagem. (ZIMMERMAN, 1998).

Estudos recentes têm mostrado que o nível de motivação vai diminuindo conforme o estudante vai avançando na escolarização (ROSÁRIO, 2015; BORUCHOVITCH, 2010). Rosário (2015) evidencia que, assim como os participantes desta pesquisa, grande parte dos estudantes do $9^{\circ}$ ano apresenta um nível muito baixo de motivação quando comparados aos demais estudantes do Ensino Fundamental. No começo do Ensino Médio, existe uma tendência de elevação do nível de motivação, em virtude da aproximação dos períodos de provas de ingresso nas universidades (ROSÁRIO, 2015). Os achados deste estudo corroboram com os dos autores supracitados, no que diz respeito à importância dos aspectos motivacionais no processo de autorregulação da aprendizagem dos alunos.

\section{Cenas 3: As esquecidas ou reprimidas}

Em uma intervenção com ateliês biográficos de formação que envolve múltiplos sujeitos é mais complexo identificar os fatos que não foram abordados explicitamente, que foram esquecidos ou reprimidos, conforme apresenta Marinas (2007). Cada sujeito que participou deste estudo tem sua história, passou por experiências escolares diferentes e possui objetivos de vida específicos. Entre as inúmeras leituras dos dados, observou-se que o contexto social estava sempre implícito (mas sempre presente) nas falas e narrativas escritas.

As etapas dos ateliês demonstraram a falta de perspectiva quanto ao futuro pessoal e profissional de grande parte dos estudantes. Os alunos dessas escolas provêm de um meio social desfavorizado e não acreditam que o estudo seja capaz de alterar esta condição. Na fala do aluno H.U.C., pode-se notar esse aspecto de forma implícita: "eu não gosto muito de estudar, mas minha mãe fala que é para eu terminar os estudos, pelo menos até o Ensino Médio, mas eu não acho que isso vai mudar a minha vida". Esse aspecto acaba interferindo também na 
motivação que leva o estudante a se engajar na atividade em sala de aula, durante seus estudos ou no desenvolvimento de outras habilidade relacionados à escola.

Muitos estudos evidenciam a interação entre boas escolas, disponibilidade de recursos e sucesso escolar e profissional. Os estudantes provenientes de condições socioeconômico-culturais mais precárias têm menos oportunidades durante todo o processo educativo, por terem que trabalhar para ajudar a família, por exemplo, ou pela precariedade da escola que frequentam. A escola deveria ter um papel de compensar as diferenças, diminuindo a desigualdade social, capacitando esses alunos. No entanto, a realidade atual brasileira não possibilita o alcance desse objetivo primordial. Esse fato esteve presente de forma indireta nas discussões dos ateliês, geralmente associadas às desmotivações com o estudo e com a dificuldade do aluno de autorregular seu processo formativo.

\section{Múltiplos fios entre as cenas: a valorização de um procedimento de formação com ateliês biográficos}

Articulando os fios entre as diversas cenas, nota-se que os ateliês biográficos de projetos valorizam a experiência e a experimentação das diversas estratégias autorregulatórias possíveis para aprender a aprender e para desenvolver o processo de aprendizagem. De acordo com Delory-Momberger (2016), a experiência tem grande importância porque permite reconhecer outras formas de aquisição do saber e da competência acadêmica e teórica. O caminho percorrido ao longo das cenas de formação-investigação provoca as reflexões sobre a construção dos processos autorregulatórios na escola e reafirma a fonte autobiográfica como uma "palavra escuta plena" (BRAGANÇA, 2014, p. 94), sendo importante não somente na interpretação de resultados, mas também na transformação dos sujeitos envolvidos.

\section{REFERÊNCIAS}

ABRAHÃO, M. H. M. B. (auto) biográfica - tempo, memória e narrativas. In: ABRAHÃO, M. H. M. B. (Org.). A Aventura (Auto) Biográfica - Teoria \& Empiria. Porto Alegre: EDIPUCRS, 2004. p. 201-224.

ABRAHÃO, M. H. M. B. Fontes orais, escritas e (áudio)visuais em pesquisa (auto) biográfica: palavra dada, escuta atenta, compreensão cênica. O studium e o punctum 
possíveis. In: ABRAHÃO, M. H. M. B.; BRAGANÇA, I. F. de S.; ARAÚJO, M. da S. (Orgs.). Pesquisa (Auto)biográfica, Fontes e Questões. Curitiba: CRV, 2014. p. 57-77.

ABRAHÃO, M. H. M. B.; FRISON, L. M. B. Narrativas (auto) biográficas de formação e o entrelaçamento com a autorregulação da aprendizagem. In: ABRAHÃO, M. H. M. B. (Org.). (Auto)biografia e Formação Humana. Natal: EDUFRN; Porto Alegre: EDIPUCRS, 2010. p. 191-216.

BANDURA, A. A teoria da evolução social cognitiva. In: BANDURA, A.; AZZI, R.; BASSO, F. P. Da formação de professores à formação de alunos: o ateliê biográfico de projetos como alternativa para desenvolver o processo de autoformação e autorregulação da aprendizagem. In: MONTEIRO, F. A.; NACARATO, A. M.; FONTOURA, H. A. (Org.) Narrativas docentes, memórias e formação. Curitiva: CRV, 2016. p. 83-96.

BASSO, F. P.; ABRAHÃO, M. H. M. B. Atividades de ensino que desenvolvem a autorregulação da aprendizagem. In: Revista Educação \& Realidade, Porto Alegre, 2017. Submetido à publicação.

BASSO, F. P.; ABRAHÃO, M. H. M. B.; FRISON, L. M. B. Relações entre a aprendizagem autorregulada e os fatos autobiográficos. Revista Galego-Portuguesa de Psicoloxía e Educación, v. extra, n. 1, 2015, p. 78-82.

BORUCHOVITCH, E. Aprender a aprender: propostas de intervenção em estratégias de aprendizagem. Educação Temática Digital, v. 8, n. 2, p. 156-167, 2007.

BORUCHOVITCH, E. motivação no contexto escolar: implicações para formação de professores. In: SANTOS, B. S., \& CARREÑO, A. B. (Org.). Autorregulação da aprendizagem e narrativas autobiográficas: epistemologia e práticas. Porto Alegre: EDIPA motivação em diferentes cenários. Porto Alegre: EdiPUCRS, 2010. p. 119-128.

BOUDAOIUN, J. M. L’épreuve autobiographique. Berne: Peter Lang, 2010.

BRAGANÇA, I. F. S. Pesquisa-Formação (Auto)Biográfica: Reflexões sobre a Narrativa Oral como Fonte e a Compreensão Cênica como Caminho de Análise. In: ABRAHÃO, M. H. M. B; BRAGANÇA, I. F. de S.; ARAÚJO, M. da S. (Org.). Pesquisa (Auto) Biográfica, fontes e questões. 1. ed. Curitiba: CRV, 2014. p. 79-95.

COSNEFROY, L. L'apprentissage autorégulé: entre cognition et motivation - déontologie et identité. Grenoble: Presses Univ. de Grenoble, 2013.

DELORY-MOMBERGER, C. Biographie et éducation, figures de l'individu projet. Paris: Anthropos, 2003.

DELORY-MOMBERGER, C. Formação e Socialização: os ateliês biográficos de projetos. Educação e Pesquisa, São Paulo, v. 32, n. 2, p. 359-371, maio/ago, 2006.

DELORY-MOMBERGER, C. Histoire de vie, processus de formation et théorie de l'apprentissage. In: SIMONET-TENANT, F. Le propre de l'écriture de soi. Paris: Téraèdre, 2007. 
DELORY-MOMBERGER, C. Le biographique: Quel espace de recherche dans les sciences humaines et sociales? In: SEMINAIRE DE RECHERCHE ET DE FORMATION A LA RECHERCHE BIOGRAPHIQUE. l'ASIVHIF-RBE. Paris, 2009.

DELORY-MOMBERGER, C. Formação e transmissão da experiência nos processos de aprendizagem e de formação.In: ABRAHÃO, M. H. M. B.; FRISON, L. M. B.; BARREIRO, C. B. A nova aventura (auto)biográfica. Tomo 1. Porto Alegre: EdiPUCRS, 2016. p.39-58.

DEMAZIÈRE, D.; DUBAR, C. Analyser les entretiens biographiques. L'exemple des récits d'insertion. Québec: Les presses de L'Université Laval, 2004.

FRISON, L. M. B.; VEIGA SIMÃO, A. M. Abordagem (auto) biográfica - narrativas de formação e de autorregulação da aprendizagem reveladas em portifólios reflexivos. Educação, v. 34, n. 2, p. 198-206, 2011.

FRISON, L. M. B.; BASSO, F. P. Construções identitárias reveladas em trabalhos com narrativas (auto)biográficas. In: ABRAHÃO, M. H. M. B.; FRISON, L. M. B.; BARREIRO, C. B. A nova aventura (auto)biográfica. Tomo 1. Porto Alegre: EdiPUCRS, 2016.

GOHARD-RADENKOVIC, A.; RACHEDI, L. Récits de vie, récits de langue et mobilité. Paris: L'Harmattan, 2009.

JOSSO, M. -C. Os relatos de histórias de vida como desvelamento dos desafios existenciais da formação e do conhecimento: destinos sócio-culturais e projetos de vida programados na invenção de si. In: SOUZA, E. C. de; ABRAHÃO, M. H. M. B. Tempos, narrativas e ficções: a invenção de si. Porto Alegre: EDIPUCRS, Salvador: EDUNEB, 2006. p. 21-40.

LEGRAND, M. L'approche biographique. Paris: Desclée de Brouwer, 1993.

MARINAS, J. M. La escucha en la historia oral. Palabra dada. Madrid: Editorial Síntesis, 2007.

MARINAS, J. M. Lo insconciente em las historias. In: ABRAHÃO, M. H. M. B; BRAGANÇA, I. F. de S.; ARAÚJO, M. da S. (Orgs.). Pesquisa (Auto)biográfica, Fontes e Questões. Curitiba: CRV, 2014. p. 39-55.

PASSEGGI, M. C.; ABRAHÃO, M. H. M. B.; DELORY-MOMBERGER, C. . Reabrir o passado, inventar o devir: a inenarrável condição biográfica do ser. In: PASSEGGI, M. C.; ABRAHÃO, M. H. M. B. (Org.). Dimensões epistemológicas e metodológicas da pesquisa (auto)biográfica. Tomo II. Vol. 1. Natal: EDUFRN; Salvador: EDUNEB; Porto Alegre: EDIPUCRS, 2012. p. 29-57.

PERRENOUD, P. Avaliação: da excelência à regulação das aprendizagens: entre duas lógicas. Porto Alegre: Artmed, 1999.

POLYDORO, S. (Org.) Teoria social cognitiva: conceitos básicos. Porto Alegre: Artmed, Cap.1, p. 15-41, 2008. 
RICOEUR. P. A memória, a história, o esquecimento. Campinas, São Paulo: Editora da UNICAMP, 2007.

RICOEUR. P. Tempo e Narrativa. São Paulo: Papirus, 1995.

ROSÁRIO, P.S.L. Autorregulação da aprendizagem em debate (painel internacional). In: I SEMINÁRIO INTERNACIONAL TEORIA SOCIAL COGNITIVA EM DEBATE, Campinas, SP, 2015.

SAMPAIO, R. K. N.; POLYDORO, S. A. J.; ROSÁRIO, P. S. L. Autorregulação da aprendizagem e a procrastinação acadêmica em estudantes universitarios. Pelotas. v. 42, p. 119-142, 2012.

SANTAMARINA, C.; MARINAS, J. M. Historias de vida y historia oral. In: DELGADO, J. M.; GUTIÉRREZ, J. (Orgs.). Métodos y técnicas cualitativas de investigación en ciencias sociales. Madrid: Síntesis, 1994.

SCHIMTZ, B.; KLUG, J.; SCHMIDT, M. Assessing self-regulated learning using diary measures with university students. In: ZIMMERMAN, B.; SCHUNK, D. (Orgs.), Handbook of Self-Regulation of Learning and Performance. New York, NY: Routledge, 2011. p. 251-266.

SILVA, J.; VEIGA SIMÃO, A. M. Entrevista com tarefa na identificação de processos na aprendizagem autorregulada. In: Psicologia Escolar e Educacional, São Paulo, SP, v. 20, n. 1, p. 89-100, 2016.

VEIGA SIMÃO, A. M.; FERREIRA, P.; DUARTE, F. Aprender estratégias autorregulatórias a partir do currículo. In: VEIGA SIMÃO, A. M.; FRISON, L.; ABRAHÃO, M. H. (Orgs.). Autorregulação da aprendizagem e narrativas autobiográficas: epistemologia e práticas. Coleção Pesquisa (Auto)Biográfica - Educação. Natal: EDUFRN; Porto Alegre: EDIPUCRS; Salvador: EDUNEB, 2012. p. 23-51.

ZIMMERMAN, B. J. Developing self-fulfilling cycles of academic regulation: An analysis of exemplary instructional models, Cap. 1. In: ZIMMERMAN, B.; SCHUNK, D. Self-regulated learning: from teaching to self-reflective practice, The Guilford press, New York/London, 1998.

ZIMMERMAN, B. J. Attaining self-regulation: A social cognitive perspective. In: BOEKAERTS, M.; PINTRICH, P.; ZEIDNER, M. (Ed.). Handbook of self-regulation. New York: Academic Press, 2000. p. 13-39.

ZIMMERMAN, B. J. From Cognitive Modeling to Self-Regulation: A Social Cognitive Career Path. Educational Psychologist, 48 (3), p. 135-147, 2013.

ZIMMERMAN, B.; RISEMBERG, R. Becoming a self-regulated writer: A social cognitive perspective. Contemporay Educational Psychology, v. 22, p. 73-101, 1997.

Texto recebido em 25 de novembro de 2016.

Texto aprovado em 13 de março de 2017. 
